\title{
SMOS and Aquarius Radiometers: Inter-Comparison Over Selected Targets
}

\author{
Miriam Pablos, Student Member, IEEE, María Piles, Member, IEEE, Verónica González-Gambau, \\ Mercè Vall-llossera, Senior Member, IEEE, Adriano Camps, Fellow, IEEE, and Justino Martínez
}

\begin{abstract}
Passive microwave remote sensing at L-band is considered to be the most suitable technique to measure soil moisture and ocean salinity. These two variables are needed as inputs of predictive models, to improve climate and weather forecast, and to increase our knowledge of the water cycle. Nowadays, there are two space missions providing frequent and global observations of moisture and salinity of the Earth's surface with L-band radiometers on-board. The first one is the ESA's SMOS satellite, launched on November 2, 2009, which carries a two-dimensional, multi-angular, and full-polarimetric synthetic aperture radiometer. The second one is the NASA/CONAE's Aquarius/SAC-D mission, launched on June 10, 2011, which includes three beam push-broom real aperture radiometers. The objective of this work is to compare SMOS and Aquarius brightness temperatures and verify the continuity and consistency of the data over the entire dynamic range of observations. This is paramount if data from both radiometers are used for any long term enviromental, meteorological, hydrological, or climatological studies. The intercomparison approach proposed is based on the study of 1 year of measurements over key target regions selected as representative of land, ice, and sea surfaces. The level of linearity, the correlation, and the differences between the observations of the two radiometers are analyzed. Results show a higher linear correlation between SMOS and Aquarius brightness temperatures over land than over sea. A seasonal effect and spatial inhomogeneities are observed over ice, at the Dome-C region. In all targets, better agreement is found in horizontal than in vertical polarization. Also, the correlation is higher at higher incidence angles. These differences indicate that there is a non-linear effect between the two instruments, not only a bias.
\end{abstract}

Index Terms-Aquarius/Satélite de Aplicaciones Científicas (SAC)-D mission, brightness temperature, inter-comparison, L-band radiometer, passive microwave remote sensing, Soil Moisture and Ocean Salinity (SMOS) mission.

Manuscript received October 10, 2013; revised February 14, 2014; accepted April 17, 2014. This work was supported by the Spanish National R+D Program on Space of the Ministry of Economy and Competitiviness, through a Formación de Personal Investigador (FPI) grant with reference BES-2011-043322, and the projects MIDAS 6: AYA2010-22062-C05-05 and MIDAS 7: AYA2012-39356C05-01.

M. Pablos, M. Piles, M. Vall-1lossera, and A. Camps are with the Remote Sensing Laboratory, Department of Signal Theory and Communications, Universitat Politècnica de Catalunya (UPC) and the Institut d'Estudis Espacials de Catalunya (IEEC), E-08034 Barcelona, Spain, and also with the Soil Moisture and Ocean Salinity Barcelona Expert Centre (SMOS-BEC), E-08003 Barcelona, Spain (e-mail: miriam.pablos@tsc.upc.edu).

V. González-Gambau and J. Martínez are with the Institut de Ciències del Mar-Consejo Superior de Investigaciones Científicas (ICM-CSIC), Department of Physical and Technological Oceanography, E-08003 Barcelona, Spain, and also with the Soil Moisture and Ocean Salinity Barcelona Expert Centre (SMOSBEC), E-08003 Barcelona, Spain.

Color versions of one or more of the figures in this paper are available online at http://ieeexplore.ieee.org.

Digital Object Identifier 10.1109/JSTARS.2014.2321455

\section{INTRODUCTION}

A MICROWAVE radiometer is a passive sensor capable of measuring the power naturally emitted by bodies at a physical temperature above $0 \mathrm{~K}$, which is proportional to the so-called brightness temperatures $\left(T_{B}\right)$ [1].

The frequency band from 1.400 to $1.427 \mathrm{GHz}$ is a protected band, reserved for radio-astronomy and passive remote sensing. At these frequencies, the amount of microwave thermal radiation naturally emitted by the Earth's surface decreases with increasing soil moisture over land [2], and increasing surface salinity in the oceans [3]. Also, this band is significantly less affected by rain and atmospheric effects than higher microwave frequencies. Not only the atmosphere is nearly transparent, but the microwave radiation emitted by the Earth's surface can also pass through the vegetation canopy (up to $5 \mathrm{~kg} / \mathrm{m}^{2}$ which corresponds to $70 \%$ of non-frozen land areas on Earth, excluding dense forest).

Currently, there are two satellite missions providing unprecedent observations of the Earth's surface using L-band radiometers: i) the Soil Moisture and Ocean Salinity (SMOS) mission [4], [5]; and ii) the Aquarius/Satélite de Aplicaciones Cientificas (SAC)-D mission [6]. The European Space Agency (ESA) launched the SMOS satellite on November 2, 2009, to monitor surface soil moisture and ocean salinity at global scale. Its single payload is the two-dimensional Microwave Imaging Radiometer with Aperture Synthesis (MIRAS), a novel instrument based on interferometry which provides multi-angular and full-polarimetric observations [7]. The Aquarius/SAC-D satellite was launched on June 10,2011, in a collaboration between the U.S. National Aeronautics and Space Administration (NASA), and the Argentinian COmisión Nacional de Actividades Espaciales (CONAE). It is devoted to monitor the Sea Surface Salinity (SSS) at global scale and includes three beam push-broom radiometers/scatterometers [8]. The NASA's Soil Moisture Active Passive (SMAP), planned to be launched on November 2014, will be the third passive L-band mission [9]. Its payloads will be a real aperture radiometer [10] and a synthetic aperture scatterometer to monitor global surface soil moisture and its freeze/thaw state.

The SMOS and Aquarius payloads operate at the same frequency band, centered at $1.413 \mathrm{GHz}$, but have important differences in both the architecture of their radiometers (e.g., number of receivers and incidence angles), as in their operation principles (e.g., interferometric vs. Dicke radiometer and Stokes parameters measured). Also, they have different swath coverage, spatial resolutions, and revisit times. The main distinctive features of SMOS and Aquarius are summarized in Table I. 
This article has been accepted for inclusion in a future issue of this journal. Content is final as presented, with the exception of pagination.

TABLE I

Main Features of SMOS and Aquarius Radiometers

\begin{tabular}{|c|c|c|}
\hline Features & SMOS & Aquarius \\
\hline Topology & $\begin{array}{l}\text { Synthetic aperture } \\
\text { Y-shape array with a diameter of } 8 \mathrm{~m}\end{array}$ & Real aperture \\
\hline Antenna type & 69 patch antennas $(0.165 \mathrm{~m}$ spaced $0.875 \lambda)$ & $2.5 \mathrm{~m}$ refiector and 3 horns \\
\hline Riddioneter unils & 72 roceivers & 3 receivers \\
\hline Stokes parameters & 4 Stokes & 3 Stokes $\left(T_{H}, T_{V}\right.$, and $\left.T_{3}\right)$ \\
\hline Operation principle & Interferometric radiometer & Dicke radiometer \\
\hline Incidence angles & From $0^{\circ}$ to $65^{\circ}$ (multi-angular) & $29.36^{\circ}$ (inner), $38.49^{\circ}$ (middle), $46.29^{\circ}$ (outer) \\
\hline Swath & $\sim 1000 \mathrm{~km}$ & $\sim 390 \mathrm{~km}$ \\
\hline Spatial resolution & $\sim 40 \mathrm{~km}$ & $\sim 100 \mathrm{~km}$ \\
\hline Revisit time & 3 days & 7 days \\
\hline Calibration performance & $\begin{array}{l}\text { Intemal (noise diode and reference load) } \\
\text { and external (cold sky views) }\end{array}$ & $\begin{array}{l}\text { Internal (noise diode and reference load), } \\
\text { model references (ocean, Antarctica and Amazon rainforest) } \\
\text { and external (cold sky views) }\end{array}$ \\
\hline
\end{tabular}

TABLE II

Corrections Applied to SMOS and Aquarius Radiometers

\begin{tabular}{llc}
\hline Correction type & SMOS & Aquarius \\
\hline Direct galaxy & Yes & Yes \\
Reflected galaxy & No & Yes \\
\hline Direct Sun & Yes & Yes \\
Reflected Sun & No & Yes \\
\hline Direct Moxon & Yes & Yes \\
Reflected Moon & No & Yes \\
\hline
\end{tabular}

Both instruments are calibrated to obtain their $T_{B}$ products within the mission requirements using different calibration procedures (see Table I). In SMOS, there are two types of calibration: the internal and the external. The internal calibration is based on the injection of uncorrelated noise, which compensates for offset terms, and correlated noise at two known levels, which compensates for amplitude and phase terms. The external calibration uses cold sky maneouvers to calibrate the injected noise level [11]. Likewise, Aquarius has an internal calibration (injecting correlated and uncorrelated noise) and uses the cold sky as external calibration. Additionally, a vicarious calibration is performed using models over the ocean, Antarctica, and Amazon rainforest [12].

After calibration, some corrections are applied to SMOS and Aquarius $T_{B}$ to obtain the signal from the Earth's surface and to filter signal contributions from celestial bodies (galaxy, Sun, and Moon). The main differences in the corrections applied are summarized in Table II. SMOS Level 1 (L1) data contain flags indicating the Sun and Moon corrections/detections in presence of direct/reflected radiations, respectively. Galaxy corrections are applied at SMOS Level 2 (L2) before retrieving the geophysical parameters. In Aquarius, $T_{B}$ are already corrected for galaxy, Sun, and Moon signal contributions.

Direct comparison of SMOS and Aquarius observations is challenging, since both are Sun-syncronous Low Earth Orbits (LEO) satellites at similar heights $(\sim 758 \mathrm{~km}$ and $\sim 675 \mathrm{~km}$, respectively), but they have opposite equatorial ascending crossing times: 6 A.M. for SMOS, 6 P.M. for Aquarius. Due to this, cross-overs only occur near the equator and at the poles.

Previous studies have shown an increased interest in comparing SMOS and Aquarius $T_{B}$. Anterrieu et al. [13] proposed a resampling and multi-windowing method to obtain SMOS $T_{B}$ at the incidence angles and ground resolution of Aquarius. Bindlish et al.
[14] used colocated overpasses (with at least 20 SMOS grid points inside the Aquarius footprint) and a 30-min time criteria to eliminate the effect of physical temperature drifts. This approach limits the observations to low latitudes between $\left[20^{\circ} \mathrm{S}, 40^{\circ} \mathrm{N}\right]$. Cabot et al. [15] used simultaneous observations over the same place (with a distance less than $2.5^{\circ}$ ) resampling SMOS data at the resolution and incidence angles of Aquarius and also obtaining a limited number of colocations ( $\sim 750$ overpasses in 500 days).

In this work, an alternative approach which does not require simultaneous cross-overs is proposed to compare SMOS and Aquarius $T_{B}$ over different targets, without latitudinal/temporal limitations. The objective is to evaluate the consistency between SMOS and Aquarius data and detect possible differences and/or biases. Key target regions over land, ice, and sea are selected to cover the entire dynamic range of $T_{B}$.

In Section II, data selection procedures as well as the intercomparison strategy are presented. Results of the analysis and evaluation of the SMOS-Aquarius inter-comparison are shown in Section III. Finally, the main conclusion and significant contributions of this study are outlined in Section IV.

\section{DATA AND METHODS}

\section{A. SMOS Data}

The SMOS $T_{B}$ at the antenna reference plane are obtained from the L1C V5.05 products, provided by the European Space Astronomy Centre (ESAC), Madrid. These $T_{B}$ have been first screened out for all the Radio-Frequency Interferences (RFI) detected (strong, point source, and tails), and also for the Sun (glint area, aliases, and tails), and Moon (aliases) contamination, using the corresponding flags. Later, geometric and Faraday corrections are applied to obtain $T_{B}$ at the top of the atmosphere (TOA):

$$
\left(\begin{array}{l}
T_{B_{H}} \\
T_{B_{V}}
\end{array}\right)=\frac{1}{\cos ^{2}(\varphi)-\sin ^{2}(\varphi)}\left(\begin{array}{cc}
\cos ^{2}(\varphi) & -\sin ^{2}(\varphi) \\
-\sin ^{2}(\varphi) & \cos ^{2}(\varphi)
\end{array}\right)\left(\begin{array}{c}
T_{B_{X}} \\
T_{B_{Y}}
\end{array}\right)
$$

where $\varphi$ is the rotation angle (geometric + Faraday), $T_{B_{X}}$ and $T_{B_{Y}}$ are the $T_{B}$ at the antenna plane according to $X$ and $Y$ axis, and $T_{B_{H}}$ and $T_{B_{V}}$ correspond to the $T_{B}$ at TOA for horizontal and vertical polarizations, respectively. 
All SMOS $T_{B}$ in an incidence angle range of $\theta \pm 5^{\circ}$ are linearly interpolated to obtain them at the Aquarius incidence angles $(\theta)$. Finally, $T_{B}$ from the Icosahedral Snyder Equal Area (ISEA 4H9) grid [16] are interpolated to a $0.25^{\circ}$ regular latitudelongitude grid, which is easier to manipulate.

\section{B. Spatial Bias Correction in SMOS Data Over Ocean}

SMOS' synthetic imagery can be interpreted as obtained by an array of antennas located in each spatial frequency point [17]. The incidence angle, the spatial resolution, and the radiometric accuracy vary depending on the position of each pixel within the Field Of View (FOV). The differences between pixels that remain after calibration are the so-called pixel biases or spatial errors.

It is known that SMOS pixel biases are significantly affecting ocean observations, since they have an important impact in SSS retrievals. Several studies characterize these spatial errors and describe methods to mitigate their effects on the $T_{B}$ images. Camps et al. [18] proposed an improved reconstruction algorithm that decomposes the visibility samples in ocean and land/ iced sea. Torres et al. [19] demonstrated that SMOS pixel biases are not zero mean and produce visible artifacts along-track, which could be minimized over the ocean using a multiplicative mask. Gourrion et al. [20] distinguished the spatial errors by azimuth dependence/independence and computed an empirically fitted pattern that could be applied over ocean, ice, and land.

In this work, an Ocean Target Transformation (OTT), which models the instrumental spatial pattern of the FOV, has been applied to SMOS data over South Pacific region, as it is currently applied operationally in the L2 Ocean Salinity processor. As a result, the errors in the FOV become practically random, preserving the geophysical variation in the scene.

\section{Aquarius Data}

The Aquarius $T_{B}$ used are L2 V2.0 products provided by the Physical Oceanography Distributed Active Archive Center, managed and located at NASA's Jet Propulsion Laboratory (JPL), California. They are directly $T_{B}$ at TOA and have been masked out for RFI, reflected Sun, glint, and Moon contamination (moderate and severe flags), and also for direct Sun contamination (severe flag). No gridding is performed.

\section{Inter-Comparison Methodology}

The inter-comparison procedure involves identifying locations on Earth that could serve as target regions to assess the behavior of both SMOS and Aquarius instruments. The main goal is to evaluate the $T_{B}$ acquired independently over several relatively stable and homogeneous targets at scales compatible with both sensors. They should have nearly constant observed $T_{B}$ over time and cover, as much as possible, the whole dynamic range of $T_{B}$ observations from the cold to the hot end (sea, ice, and land). Attending to these criteria, four locations have been selected: 1) the Amazon rainforest, 2) the Sahara desert, 3) the South Pacific Ocean, and 4) the Dome-C zone in Antarctica (Fig. 1). Specific locations, areas, and number of observations selected from each radiometer are included in Table III. Observations from cold sky views have not been used in this study since both radiometers have different antenna patterns and also

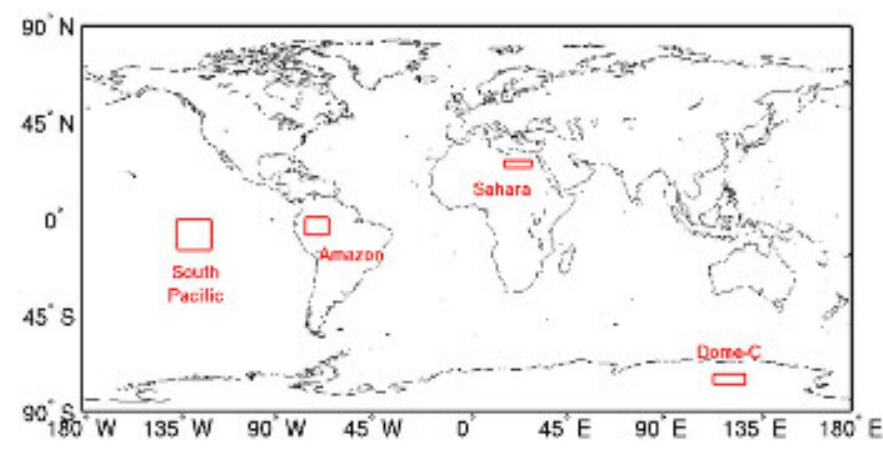

Fig. 1. World map showing location and extention of target regions: Amazon rainforest and Sahara desert (land), South Pacific Ocean (sea), and Dome-C in Antarctica (ice).

different scenes entering into the back lobes that could severely affect the $T_{B}$ measurements from the main lobe $(\sim 3-10 \mathrm{~K})$.

The four target regions selected for the present study have different radiometric characteristics.

1) The Amazon tropical forest has a very stable temperature and its surface is covered by a heavily vegetated layer that provides a feasible approximation to a blackbody at L-band. However, its surface contains rivers and it rains almost the whole year.

2) The Sahara's surface is very dry, sandy, and without presence of vegetation. It is characterized by a dry atmosphere and high daily surface temperature variations. In the Sahara desert, the area has been selected to ensure total absence of precipitation during the study period. It was checked using the total precipitation in $(\mathrm{mm} / \mathrm{month})$ of the Global Precipitation Climatology Centre (GPCC) using a $1^{\circ}$ regular grid product based on quality-controlled data from Earth's stations.

3) The South Pacific ocean is an ice-free region on the sea, with low or moderate Wind Speed (WS $<12 \mathrm{~m} / \mathrm{s}$ ), an almost constant Sea Surface Temperature (SST) of $\sim 26.5^{\circ} \mathrm{C}$, and a SSS of $\sim 35$ psu.

4) The Dome-C in Antarctica is considered a very stable region on Earth. Also, Dome-C has been suggested as a reference target for several experimental campaigns [21], [22].

All SMOS and Aquarius radiometric observations measured over the selected target areas have been analyzed at the three Aquarius Earth incidence angles along the year 2012. For Aquarius, only the footprints which are entirely enclosed within the target areas' boundaries have been considered. In SMOS, the orbits covering at least $20 \%$ of the total number of ISEA $4 \mathrm{H} 9$ grid points within the region have been taken into account. Both ascending and descending orbits have been used. The use of ascending and descending separately has been checked not to affect the results.

Temporal window averaging is needed to reduce the noise in the measurements. To select an appropriate length for this window, the Allan variance has been computed over each target region, both for SMOS and for Aquarius. Allan variance determines the stability and drifts of the measurement time series as a function of the integration time (in this study from 2 to 100 days). Plots of the Allan variance obtained for Aquarius (top) and 
This article has been accepted for inclusion in a future issue of this journal. Content is final as presented, with the exception of pagination.

TABLE III

Description of Selected Target Areas

\begin{tabular}{|c|c|c|c|c|c|}
\hline Location & Lititude & Longitude & Arca $\left(\mathrm{km}^{2}\right)$ & Beam & SMOS / Aquarius (pixels) \\
\hline \multirow{3}{*}{ Amazon } & \multirow{3}{*}{$8^{\circ} \mathrm{S}, 1^{\circ} \mathrm{N}$} & \multirow{3}{*}{$75^{\circ} \mathrm{W}, 65^{\circ} \mathrm{W}$} & \multirow{3}{*}{$1113 \times 10^{3}$} & Inner & $294697 / 22618$ \\
\hline & & & & Middle & $289987 / 26886$ \\
\hline & & & & Ouler & $335133 / 23001$ \\
\hline \multirow{3}{*}{ Sahara } & \multirow{3}{*}{$23.5^{\circ} \mathrm{N}, 27.5^{\circ} \mathrm{N}$} & \multirow{3}{*}{$18^{\circ} \mathrm{E}, 30^{a} \mathrm{E}$} & \multirow{3}{*}{$593 \times 10^{3}$} & Inner & $164074 / 11485$ \\
\hline & & & & Middle & $162554 / 11216$ \\
\hline & & & & Outer & $181238 / 10485$ \\
\hline \multirow{3}{*}{ South Pacific } & \multirow{3}{*}{$15^{\circ} \mathrm{S}, 0^{\circ} \mathrm{N}$} & \multirow{3}{*}{$135^{\circ} \mathrm{W}, 120^{\circ} \mathrm{W}$} & \multirow{3}{*}{$2782 \times 10^{3}$} & Inner & $712923 / 66141$ \\
\hline & & & & Middle & $711083 / 64374$ \\
\hline & & & & Outer & $393666 / 62707$ \\
\hline \multirow{3}{*}{$\begin{array}{l}\text { South Pacific } \\
\text { (with OTT applied } \\
\text { to SMOS data) }\end{array}$} & \multirow{3}{*}{$15^{\circ} \mathrm{S}, 0^{\circ} \mathrm{N}$} & \multirow{3}{*}{$135^{\circ} \mathrm{W}, 120^{\circ} \mathrm{W}$} & \multirow{3}{*}{$2382 \times 10^{3}$} & Inner & $712925 / 66141$ \\
\hline & & & & Middle & $706166 / 64374$ \\
\hline & & & & Outer & $793577 / 62707$ \\
\hline \multirow{3}{*}{ Dome-C } & \multirow{3}{*}{$78^{\circ} \mathrm{S}, 72^{\circ} \mathrm{S}$} & \multirow{3}{*}{$116^{\circ} \mathrm{E}, 130^{\circ} \mathrm{E}$} & \multirow{3}{*}{$1039 \times 10^{3}$} & Inner & $1450060 / 30904$ \\
\hline & & & & Middle & $1444861 / 34732$ \\
\hline & & & & Outer & $1737110 / 38305$ \\
\hline
\end{tabular}
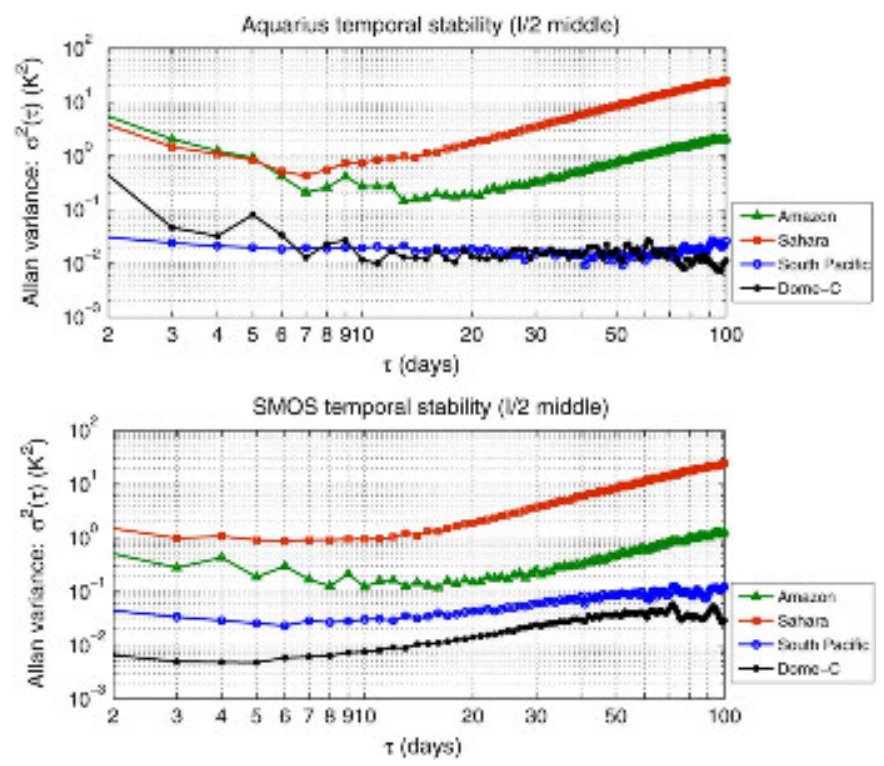

Fig. 2. Aquarius (top) and SMOS (bottom) Allan variance for each target region: Amazon (green), Sahara (red), South Pacific (blue), and Dome-C (black) using only middle beam of the First Stokes (I/2). Other beams present similar behaviors.

SMOS (bottom) over all targets using the middle beam of the First Stokes parameter $\left(I / 2=\left(T_{B_{H}}+T_{B_{V}}\right) / 2\right)$ are shown in Fig. 2. Other beams (not included) present similar behavior. It could be observed that Aquarius has a stability period of $\sim 7$ days over land and ice, in agreement with its revisit time. Over ocean, the stability period is not clear enough. SMOS has a stability period of $\approx 6-10$ days over land, $\approx 3-7$ days over ice, and $\approx 5-8$ days over ocean. In view of these results, a 7-day averaging window has been selected in this study for all target regions and both instruments.

\section{RESULTS OF SMOS-AQUARIUS INTER-COMPARISON}

SMOS and Aquarius $T_{B}$ have been compared at TOA for horizontal and vertical polarizations separately, at the three Aquarius incidence angles: $\sim 29.36^{\circ}$ (inner), $\sim 38.49^{\circ}$ (middle), and $\sim 46.29^{\circ}$ (outer) beams. First Stokes has also been analyzed to discard errors due to Faraday rotation.
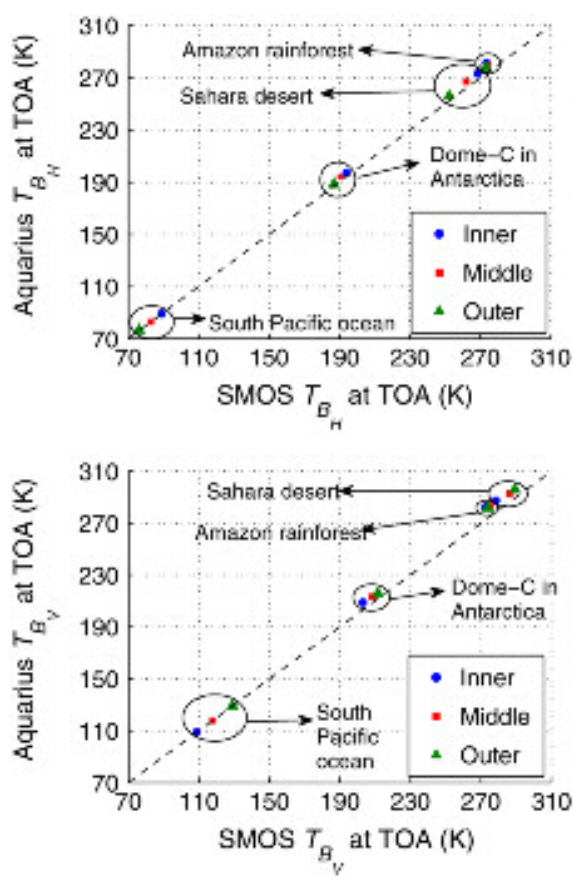

Fig. 3. Aquarius $T_{B}$ versus SMOS $T_{B}$ over land $\sim 250-300 \mathrm{~K}$ (Amazon rainforest and Sahara desert), over ice $\sim 180-220 \mathrm{~K}$ (Dome-C in Antarctica), and over sea $\sim 70-130 \mathrm{~K}$ (South Pacific ocean) for horizontal (top) and vertical polarizations (bottom). Different symbols represent inner (blue circles), middle (red squares), and outer (green triangles) beams.

A global view of the results over all the study areas (Amazon, Sahara, South Pacific, and Dome-C) is provided in Fig. 3. The yearly mean Aquarius $T_{B}$ are presented as a function of the yearly mean SMOS $T_{B}$ for each beam, polarization, and region. Each beam is depicted using a different color and symbol. Ideally, the yearly mean values within the dynamic range $(70-310 \mathrm{~K})$ should be on the 1:1 line (dashed line).

In South Pacific, Dome-C, and Sahara, higher incidence angles imply lower $T_{B_{H}}$, and higher $T_{B_{V}}$. However, in the Amazon, the $T_{B}$ variation with incidence angle and polarization is not clear due to the vegetation scattering; the signal emitted by the Amazon's surface is highly affected by multiple reflections when it is traveling upward through the vegetation canopy, and coherent effects appear when the distance 
between vegetation scatterers becomes comparable to the wavelength $(\sim 21 \mathrm{~cm})$. As expected, there is a small difference between polarizations $\left(T_{B_{V}}-T_{B_{H}}\right)$ for vegetation-covered soils.

To study the linearity between the two radiometers, representative scatter plots of Aquarius $T_{B}$ versus SMOS $T_{B}$ (7-day averaged) are presented for horizontal (Fig. 4) and vertical (Fig. 5) polarizations. Regions are sorted by rows and beams are assigned by columns. Dynamic ranges are fixed for each area to show full $T_{B}$ variability with enough detail. The slope $s$ is estimated through a robust linear fit [23].

Over land, the slopes are close to 1 (Amazon: $s \approx 0.94$ to 1.21, Sahara: $s \approx 0.86$ to 1.05 ). Over sea, slopes are low and only slightly increase after the pixel bias correction (South Pacific: before OTT $s \approx 0.08$ to 0.37 , after OTT $s \approx 0.30$ to 0.42 ). It is evident from these results that there is a better agreement between SMOS and Aquarius $T_{B}$ over land than over sea. In the case of Dome-C, the scatter plots show an unusual distribution and two slopes (opposite in sign) have been identified. The subset of points from the summer months (from December 21 to March 21) match with positive slopes (Dome-C Austral summer: $s \approx 0.30$ 1.66), whereas the other points match with negative slopes (Dome-C other seasons: $s \approx-0.11$ to -0.58 ). Note that some slopes over ice are non-significant $(p>0.05)$ for middle and outer beams. Focusing on a single target area and comparing the different polarizations, it can be noted that $T_{B_{H}}$ slopes are higher than $T_{B_{V}}$ slopes. Also, the slope values obtained at higher incidence angles are closer to 1 (ideal slope) than lower incidence angles in most cases.

Fig. 6 shows scatter plots of Aquarius $I / 2$ versus SMOS $I / 2$. Results are in line with those obtained in Figs. 4 and 5. Scatter plots over land present a very linear trend (Amazon: $s \approx 0.96-$ 1.20 , Sahara: $s \approx 0.88-1.01$ ). Slopes decrease over sea (South Pacific: before OTT $s \approx 0.15-0.27$, after OTT $s \approx 0.37-0.40$ ), and are far away from the 1:1 line. This may probably be due to the reduced dynamic range. Over Dome-C, the slopes are also in agreement with horizonal and vertical polarization (Dome-C Austral summer: $s \approx 1.19-1.56$, other seasons: $s \approx-0.31$ to -0.77 ). Note that $I / 2$ is independent of the Faraday rotation and results obtained with $I / 2$ are consistent with those obtained with $T_{B_{H}}$ and $T_{B_{V}}$. This confirms that differences in Faraday correction are not affecting the comparison.

Statistical scores, namely, the mean, the standard deviation (std), the root-mean-square difference (RMSD), the Spearman correlation (R), the $T_{B}$ difference (Aquarius $T_{B}$ minus SMOS $\left.T_{B}\right)$, and the slope $(s)$ are displayed for horizontal, vertical polarization, and First Stokes in Tables IV-VI, respectively. Non-significant correlations or slopes $(p>0.05)$ are marked with an asterisk. Results are in agreement with the corresponding scatter plots in Figs. 4-6. Correlation is very strong over land $(\mathrm{R}>0.9)$ and decreases over sea (before OTT: $\mathrm{R} \approx 0.23-$ 0.68 , after OTT: $\mathrm{R} \approx 0.63-0.80$ ). Over ice, the correlations are $\mathrm{R} \approx 0.74-0.96$ in the Austral summer and $\mathrm{R} \approx 0.24-0.65$ during other seasons. Correlation and slope values are systematically higher at horizontal than at vertical polarization. This result reveals that there is a higher degree of linearity between SMOS and Aquarius at horizontal than at vertical polarizations.
Note that Aquarius $T_{B}$ are warmer than SMOS $T_{B}$ over all study areas. The difference is higher over warmer targets with $\sim 5 \mathrm{~K}(\sim 8 \mathrm{~K})$ for horizontal (vertical) polarization over land. This difference decreases with colder targets being $\sim 3 \mathrm{~K}$ $(\sim 5 \mathrm{~K})$ for horizontal (vertical) polarization over ice and $\sim 0.6 \mathrm{~K}(\sim 2 \mathrm{~K})$ for horizontal (vertical) polarization over sea. In the latter, the difference decreases significantly after applying the pixel bias correction down to $\sim 0.3 \mathrm{~K}(\sim 0.1 \mathrm{~K})$ for horizontal (vertical) polarization. It has been checked that differences over sea are not due to different wind conditions, affecting SMOS and Aquarius during the 7-day period. Since the difference between SMOS and Aquarius $T_{B}$ is found to be target dependent, it can be argued that there is a bias and also a nonlinear effect between the two instruments.

The noise level of each instrument is calculated from the temporal standard deviation of the observations. In percent (std divided by mean), Aquarius noise varies from $\approx 0.2 \%$ to $0.4 \%$ over sea, from $\approx 0.5 \%$ to $1.5 \%$ over ice, and from $\approx 0.4 \%$ to $1.4 \%$ over land. SMOS noise varies from $\approx 1.3 \%$ to $2.5 \%$ over sea, from $\approx 1.5 \%$ to $3 \%$ over ice, and from $\approx 1.7 \%$ to $3.5 \%$ over land. This is consistent with the topology of the radiometers, since Aquarius is a real aperture Dicke radiometer and SMOS is a synthetic aperture radiometer, which involves $T_{B}$ image reconstruction. Currently, the OTT reduces the image pixel biases within the FOV to a large extent. In this study, the application of the OTT results in an improvement of $\sim 30 \%-40 \%$ in South Pacific, obtaining a noise level from $\approx 0.8 \%$ to $1.5 \%$ over sea.

Temporal evolution of SMOS and Aquarius $T_{B}$ during year 2012 has also been analyzed. The $T_{B}$ variations are displayed in Fig. 7. The corresponding yearly mean value has been subtracted $\left(\Delta T_{B_{p o l}}=T_{B_{p o l}}-\overline{T_{B_{p o l}}}\right.$, where the subscript pol indicates the polarization $\mathrm{H}$ or $\mathrm{V}$ for horizontal and vertical, respectively), in order to show the full variability with enough detail. Dynamic ranges are also fixed, being $6 \mathrm{~K}$ for Amazon, $20 \mathrm{~K}$ for Sahara, $3 \mathrm{~K}$ for South Pacific, and $2 \mathrm{~K}$ for Dome-C. Results show that SMOS $T_{B}$ present higher temporal fluctuations than Aquarius ones over all regions due to the nature of the instrument.

Over land, SMOS and Aquarius $T_{B}$ have a similar seasonal behavior. In the Amazon, lower $T_{B}$ are obtained with the two radiometers during the first half of the year, coincident with the rainy season, than in the second half of the year, corresponding to the not-so-rainy season. In the Sahara, higher $T_{B}$ are observed both in SMOS and Aquarius from April to November due to the very high temperatures at that time of the year. Over sea, SMOS $T_{B}$ show higher seasonal variability than over land. In the South Pacific, SMOS $T_{B}$ have a lower variability after applying the pixel bias correction, particularly at vertical polarization. In Dome-C, both radiometers show a more stable $T_{B}$ at vertical than at horizontal polarization, which may be due to Sun scattering contributions, since the reflection coefficient is larger at horizontal than at vertical polarization. A seasonal phenomenon is also observed. The SMOS and Aquarius $T_{B}$ vary in phase along time during the Austral summer. In contrast, SMOS and Aquarius $T_{B}$ vary in opposite phase in the other seasons. One reason for this may be that Sun zenith angle variations are affecting SMOS and Aquarius observations in a different way, depending on the period of the year. Also, the upper $10 \mathrm{~m}$ 
This article has been accepted for inclusion in a future issue of this journal. Content is final as presented, with the exception of pagination.
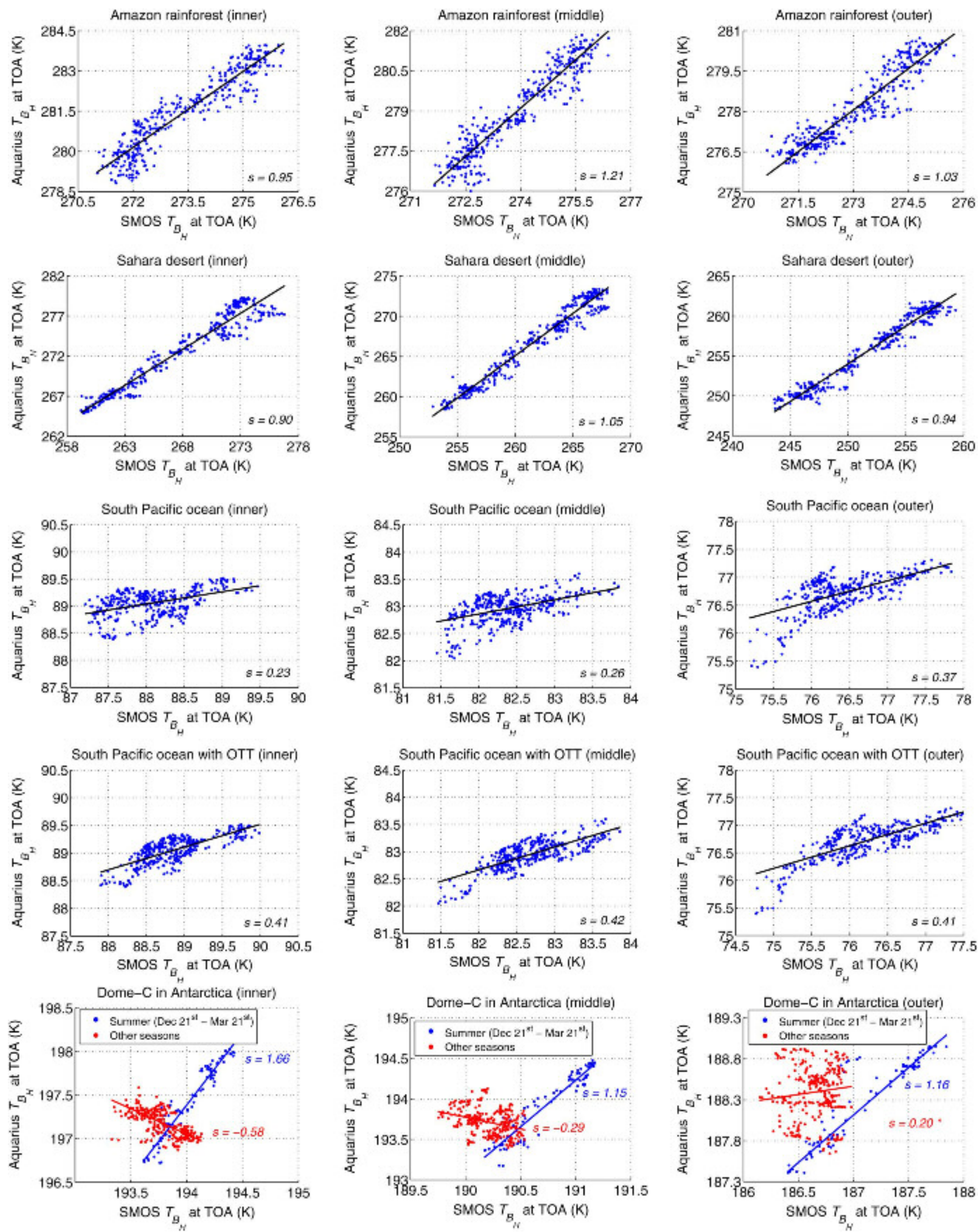

Fig. 4. Scatter plots of Aquarius $T_{B_{H}}$ versus SMOS $T_{B_{H}}$ over target areas sorted by rows: Amazon rainforest, Sahara desert, South Pacific Ocean without OTT applied to SMOS data (third row), South Pacific ocean with OTT applied to SMOS data (fourth row), and Dome-C in Antarctica. Different incidence angles are placed by columns: inner $\sim 29.36^{\circ}$ (left), middle $\sim 38.49^{\circ}$ (center), and outer $\sim 46.29^{\circ}$ (right) beams. Dynamic ranges are fixed, being $6 \mathrm{~K}$ for Amazon, $20 \mathrm{~K}$ for Sahara, $3 \mathrm{~K}$ for South Pacific, and $2 \mathrm{~K}$ for Dome-C. Over Dome-C, the Austral summer (in blue) is distinguished from the rest of the seasons (in red). The solid line represents the robust linear regression. Slope values $s$ from the linear fit are shown in the plots. Non-significant slopes $(p>0.05)$ are marked with an asterisk. 

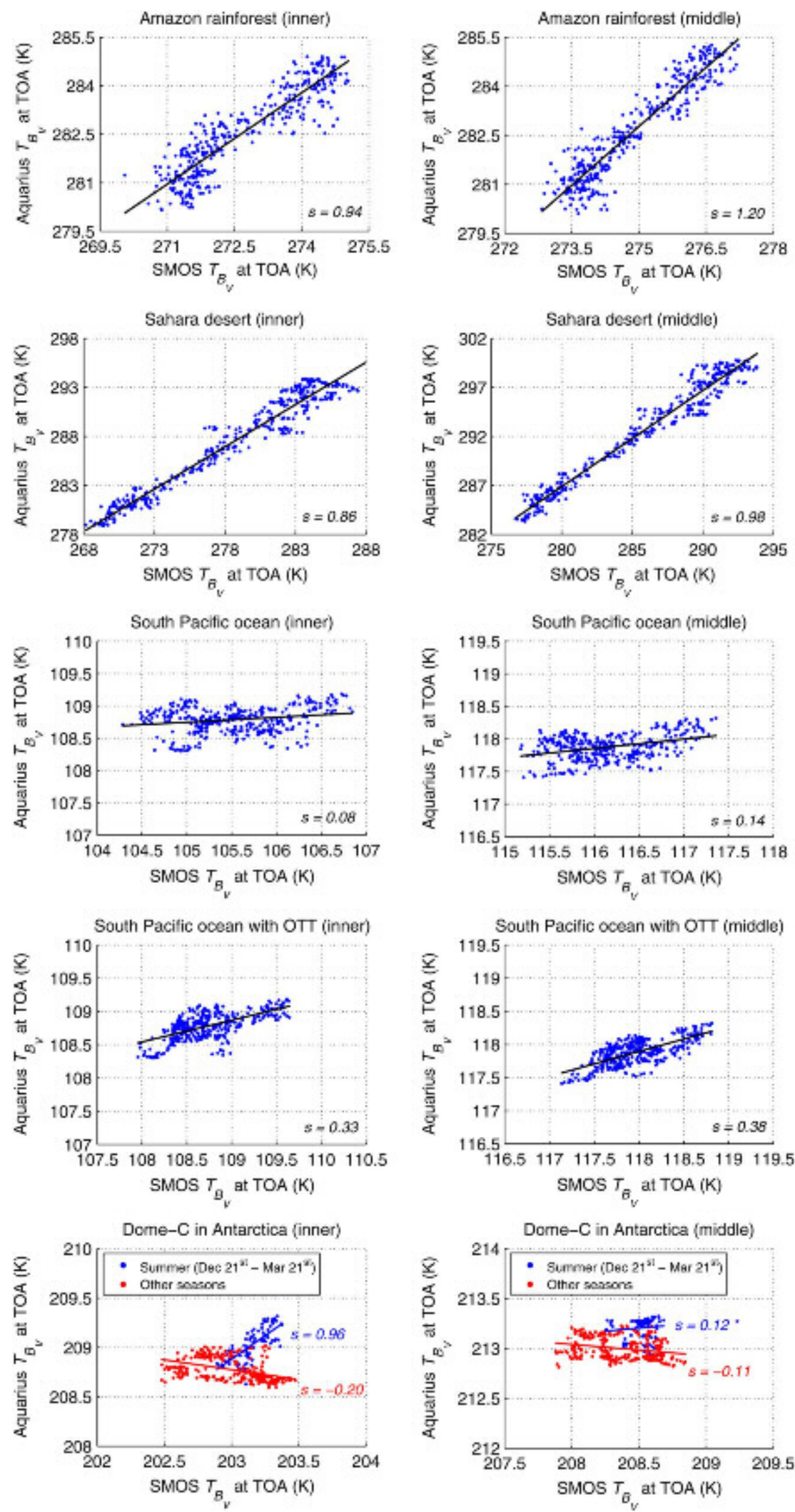
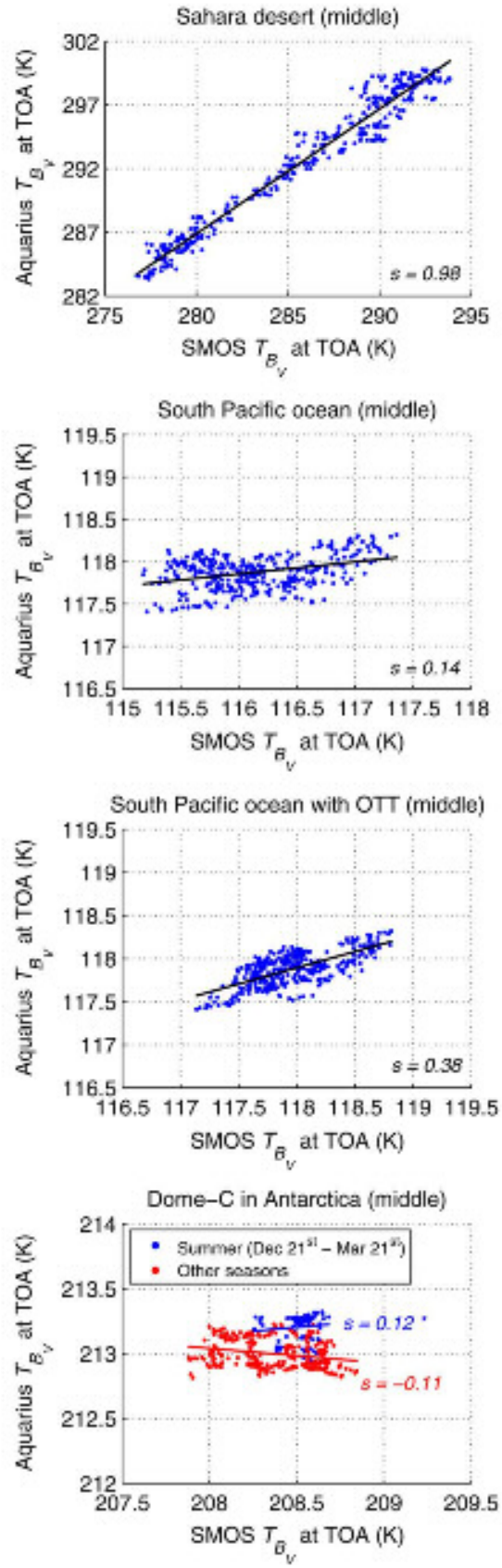
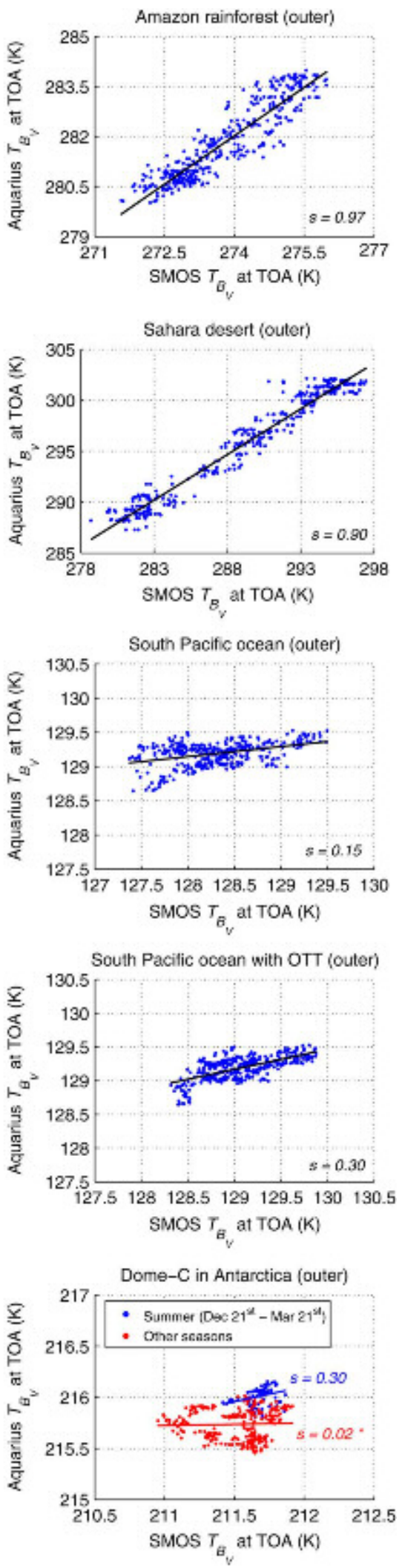

Fig. 5. Same as for Fig. 4, but at vertical polarization $\left(T_{B_{V}}\right)$.

experience seasonal temperature changes in the order of $30^{\circ} \mathrm{C}$ [24]. We assume that these temperature variations could affect the ice crystal size and shape, modifying the microwave emission of the ice surface in scales resolved by SMOS and not by Aquarius. Spatial inhomogeneities over the Dome-C area were found in a recent airborne campaign using the EMIRAD-2 L-band radiometer [25]. Expected high values of $T_{B}$ appeared in the Northern side, while other unexpected 

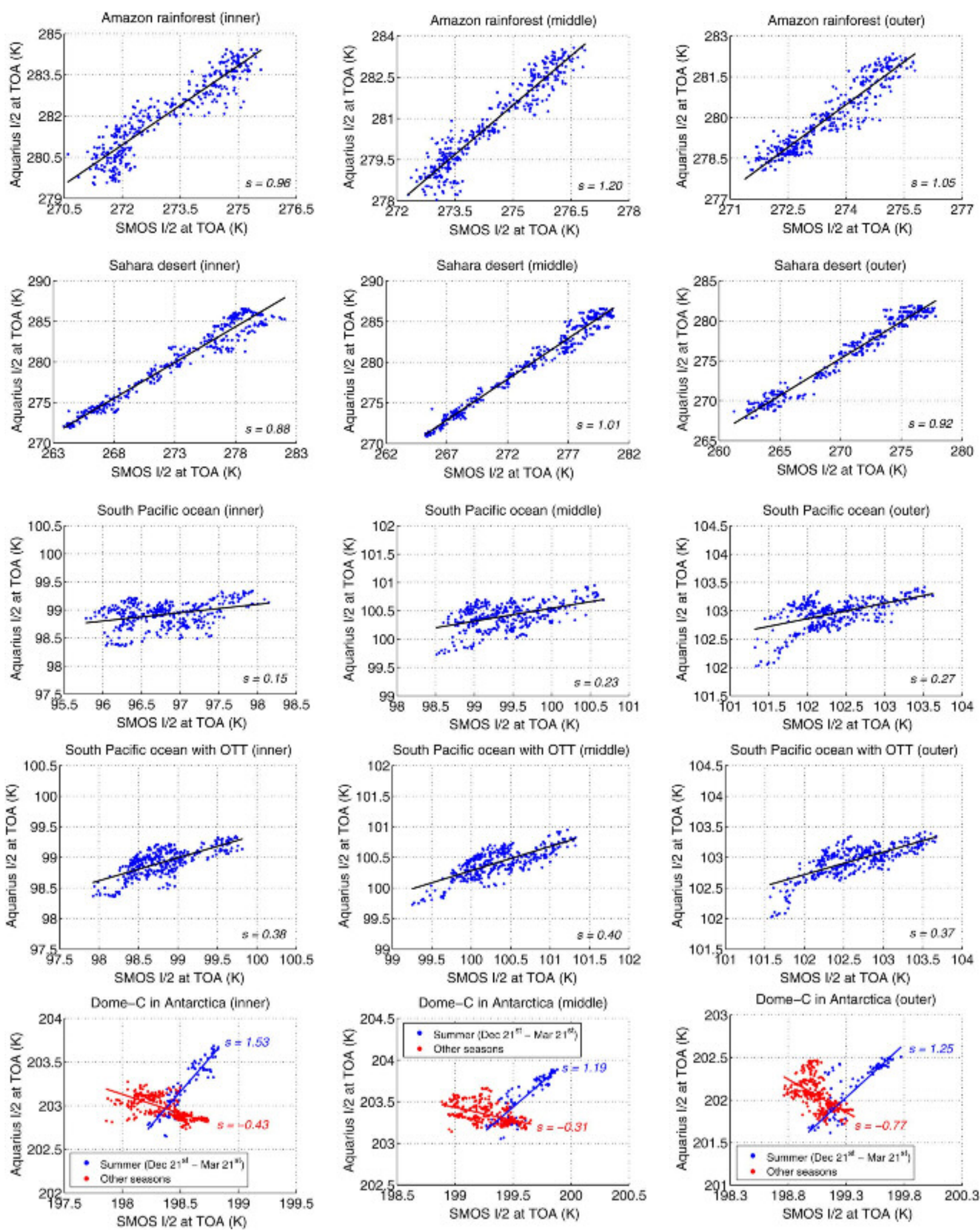

Fig. 6. Same as for Fig. 4, but for First Stokes $(I / 2)$.

inhomogeneities were observed around Concordia station and the Western side.

Theoretically, the L-band penetration depth of ice and snow is of hundreds of meters. As ice and snow at Dome-C are very dry, we thought that L-band penetration in this area could be more than hundreds of meters. In view of the results presented in this paper, we hypothesize the penetration depth may be significantly higher and $T_{B}$ observations are being influenced by geophysical 
This article has been accepted for inclusion in a future issue of this journal. Content is final as presented, with the exception of pagination.

TABLE IV

Statistics for Horizontal Polarization $\left(T_{B_{H}}\right)$

\begin{tabular}{|c|c|c|c|c|c|c|c|}
\hline \multirow{2}{*}{ Targel region } & \multirow{2}{*}{ Bearn } & \multirow{2}{*}{$\begin{array}{c}\text { Aquarius } \\
\text { mean } \pm \text { std }(K)\end{array}$} & \multirow{2}{*}{$\begin{array}{c}\text { SMOS } \\
\text { mean } \pm \text { std }(\mathbf{K})\end{array}$} & \multicolumn{3}{|c|}{ Aquarius-SMOS } & \multirow{2}{*}{ Slope s } \\
\hline & & & & $\operatorname{RMSD}(\mathrm{K})$ & $\mathrm{R}$ & Difference $(\mathrm{K})$ & \\
\hline \multirow{3}{*}{ Amazon } & Inner & $281.46 \pm 2.49$ & $273.41 \pm 6.48$ & 8.07 & 0.94 & 8.05 & 0.95 \\
\hline & Midille & $278.93 \pm 3.76$ & $273.88 \pm 5.69$ & 5.09 & 0.94 & 5.05 & 1.21 \\
\hline & Ouler & $278.18 \pm 3.17$ & $273.12 \pm 6.52$ & 5.08 & 0.93 & 5.05 & 1.03 \\
\hline \multirow{3}{*}{ Sahara } & Inner & $273.15 \pm 1.20$ & $268.38+7.31$ & 4.95 & 0.97 & 4.73 & 0.90 \\
\hline & Middle & $267.05 \pm 1.17$ & $261.89 \pm 6.97$ & 5.25 & 0.98 & 5.16 & 1.05 \\
\hline & Outer & $256.05+1.98$ & $252.22 \pm 8.96$ & 3.94 & 0.98 & 3.83 & 0.94 \\
\hline \multirow{3}{*}{ South Pacific } & Inner & $89.04 \pm 0.29$ & $88.08 \pm 1.88$ & 1.06 & 0.48 & 0.96 & 0.23 \\
\hline & Middle & $82.95 \pm 0.29$ & $82.39 \pm 2.16$ & 0.69 & 0.56 & 0.56 & 0.26 \\
\hline & Outer & $36.70 \pm 0.32$ & $76.40+1.88$ & 0.49 & 0.68 & 0.30 & 0.37 \\
\hline \multirow{3}{*}{$\begin{array}{c}\text { South Paxific } \\
\text { (with OTT applied } \\
\text { to SMOS data) }\end{array}$} & lnner & $89.04 \pm 0.29$ & $88.85 \pm 1.05$ & 0.35 & 0.76 & 0.19 & 0.41 \\
\hline & Middle & $82.95 \pm 0.29$ & $82.67 \pm 1.04$ & 0.42 & 0.78 & 0.28 & 0.42 \\
\hline & Outer & $76.70 \pm 0.32$ & $76.20 \pm 1.13$ & 0.63 & 0.80 & 0.50 & 0.41 \\
\hline Dome-C & Inner & $197.45 \pm 3.07$ & $194.04 \pm 4.80$ & 3,42 & 056 & 3,41 & 1,66 \\
\hline (Asstraf & Middlle & $193.93 \pm 2.81$ & $190.74 \pm 4.78$ & 3,19 & 0.95 & 3,19 & 1.15 \\
\hline simmer) & Outer & $188.32 \pm 2.67$ & $187.12 \pm 5.50$ & 1.21 & 0.91 & 1.20 & 1,16 \\
\hline Dome-C: & Inner & $197.18+2.78$ & $193.78+4.86$ & 3.41 & 0.65 & 3.40 & -0.58 \\
\hline (other & Midklle & $193.72 \pm 2.64$ & $190.21 \pm 4.81$ & 3.52 & 0.33 & 3.51 & -0.29 \\
\hline seasons) & Ouler & $188.38 \pm 2.40$ & $186.64 \pm 5.47$ & 1.77 & $0.07^{*}$ & 1.74 & $0.20 \%$ \\
\hline
\end{tabular}

*Non-significant values of correlations or slopes $(p>0.05)$.

TABLE V

Statistics for Vertical Polarization $\left(T_{B_{V}}\right)$

\begin{tabular}{|c|c|c|c|c|c|c|c|}
\hline \multirow{2}{*}{ Targel region } & \multirow{2}{*}{ Bearn } & \multirow{2}{*}{$\begin{array}{c}\text { Aquarius } \\
\text { mean } \pm \text { std }(K)\end{array}$} & \multirow{2}{*}{$\begin{array}{c}\text { SMOS } \\
\text { mean } \pm \text { std }(\mathrm{K})\end{array}$} & \multicolumn{3}{|c|}{ Aquarius-SMOS } & \multirow{2}{*}{ Slope 5} \\
\hline & & & & RMSD (K) & $\mathrm{R}$ & Differeace $(\mathrm{K})$ & \\
\hline \multirow{3}{*}{ Amszon } & Inner & $282.55 \pm 2.19$ & $272.70 \pm 5.63$ & 9.86 & 0.91 & 9.85 & 0.94 \\
\hline & Middle & $282.67 \pm 3.31$ & $274.92 \pm 5.17$ & 7.77 & 0.94 & 7.75 & 1.20 \\
\hline & Ouler & $281.84 \pm 2.39$ & $273.80 \pm 4.57$ & 8.05 & 0.92 & 8.03 & 0.97 \\
\hline \multirow{3}{*}{ Sahara } & Inner & $287.37 \pm 1.17$ & $278.50 \pm 7.43$ & 8.97 & 0.97 & 8.87 & 0.86 \\
\hline & Middle & $292.88+1.06$ & $286.10+7.89$ & 6.86 & 0.98 & 6.78 & 0.98 \\
\hline & Outer & $295.86+1.76$ & $289.27 \pm 9.30$ & 6.69 & 0.98 & 6.59 & 0.90 \\
\hline \multirow{3}{*}{ South Pacific } & lnner & $108.78 \pm 0.29$ & $105.52 \pm 1.94$ & 3.30 & 0.23 & 3.26 & 0.08 \\
\hline & Middle & $117.87 \pm 0.28$ & $116.13 \pm 2.01$ & 1.80 & 0.38 & 1.74 & 0.14 \\
\hline & Outer & $129.19 \pm 0.27$ & $128.31 \pm 1.63$ & 0.97 & 0.43 & 0.88 & 0.15 \\
\hline South Pacific & Inner & $108.78 \pm 0.29$ & $108.74 \pm 1.04$ & 0.30 & 0.63 & 0.04 & 0.33 \\
\hline (with OTT applied & Middle & $117.87 \pm 0.28$ & $117.94 \pm 1.02$ & 0.27 & 0.69 & -0.07 & 0.38 \\
\hline to SMOS daza) & Outer & $129.19 \pm 0.27$ & $129.06 \pm 1.09$ & 0.31 & 0.67 & 0.13 & 0.30 \\
\hline Dome-C & lnner & $209.02 \pm 2.22$ & $203.15 \pm 3.93$ & 5.87 & 0.74 & 5.87 & 0.96 \\
\hline (Asstraf & Mioddle & $213.20 \pm 1.52$ & $208.52 \pm 3.65$ & 4.68 & $0.09^{\circ}$ & 4.68 & $0.12^{\circ}$ \\
\hline sunner) & Outer & $216.00 \pm 1.18$ & $211.68 \pm 3.15$ & 4.33 & 0.27 & 4.32 & 0.30 \\
\hline Dome $\mathrm{C}$ & Inner & $2018.78 \pm 2.03$ & $202.99 \pm 3.81$ & 5.79 & 0.42 & 5.79 & 0.20 \\
\hline (other & Midkdle & $213.00 \pm 1.45$ & $205.36 \pm 3.63$ & 4.65 & 0.24 & 4.64 & -0.11 \\
\hline secasons! & Ouler & $215.73 \pm 1.17$ & $211.52 \pm 2.95$ & 4.22 & $0.03^{\circ}$ & 4.21 & $0.02^{5}$ \\
\hline
\end{tabular}

*Non-significant values of correlations or slopes $(p>0.05)$.

TABLE VI

Statistics For First Stokes $(I / 2)$

\begin{tabular}{|c|c|c|c|c|c|c|c|}
\hline \multirow{2}{*}{ Target region } & \multirow{2}{*}{ Beam } & \multirow{2}{*}{$\begin{array}{c}\text { Aquarius } \\
\text { mean } \pm \text { std }(\mathrm{K})\end{array}$} & \multirow{2}{*}{$\begin{array}{c}\text { SMOS } \\
\text { mean } \pm \text { std }(\mathrm{K})\end{array}$} & \multicolumn{3}{|c|}{ Aquarius-SMOS } & \multirow{2}{*}{ Slope $s$} \\
\hline & & & & $\operatorname{RMSD}(\mathrm{K})$ & $\mathrm{R}$ & Difference $(\mathrm{K})$ & \\
\hline \multirow{3}{*}{ Amazon } & Inner & $282.00 \pm 2.33$ & $273.12 \pm 5.19$ & 8.90 & 0.93 & 8.88 & 0.96 \\
\hline & Middle & $280.80 \pm 3.54$ & $274.44 \pm 4.84$ & 6.38 & 0.95 & 6.36 & 1.20 \\
\hline & Outer & $280.00 \pm 2.77$ & $273.55 \pm 4.31$ & 6.46 & 0.94 & 6.45 & 1.05 \\
\hline \multirow{3}{*}{ Sahara } & Innet & $280.26 \pm 1.15$ & $273.42 \pm 5.77$ & 6.96 & 0.97 & 6.84 & 0.88 \\
\hline & Middle & $279.97+0.99$ & $274.96 \pm 5.91$ & 5.97 & 0.99 & 5.91 & 1.01 \\
\hline & Outer & $275.96+1.76$ & $270.73+7.26$ & 5.30 & 0.98 & 5.23 & 0.92 \\
\hline \multirow{3}{*}{ South Pacific } & Inner & $98.91 \pm 0.27$ & $96.80 \pm 1.15$ & 2.16 & 0.37 & 2.11 & 0.15 \\
\hline & Middle & $100.41 \pm 0.26$ & $99.43 \pm 1.13$ & 1.07 & 0.52 & 0.98 & 0.23 \\
\hline & Outer & $102.94 \pm 0.27$ & $102.34 \pm 1.22$ & 0.72 & 0.59 & 0.60 & 0.27 \\
\hline South Pacific & lnner & $98.91 \pm 0.27$ & $98.79 \pm 0.77$ & 0.32 & 0.71 & 0.12 & 0.38 \\
\hline (wib OTT applied & Middle & $100.41 \pm 0.26$ & $100.32 \pm 0.77$ & $0.3 \mathrm{I}$ & 0.75 & 0.09 & 0.40 \\
\hline to SMOS daza) & Outer & $102.94 \pm 0.27$ & $102.63 \pm 0.83$ & 0.46 & 0.76 & 0.31 & 0.37 \\
\hline Dome-C & Inner & $203.23 \pm 2.64$ & $198.55 \pm 3.68$ & 4.68 & 0.93 & 4.68 & 1.53 \\
\hline (Asstral & Middle & $203.56 \pm 2.14$ & $199.61 \pm 3.80$ & 3.95 & 0.87 & 3.95 & 1.19 \\
\hline siviner) & Outer & $203.16 \pm 1.90$ & $199.38 \pm 3.63$ & 2.79 & 0.85 & 2.78 & 1.25 \\
\hline Dome C: & Inner & $202.98 \pm 2.39$ & $198.35 \pm 3.61$ & 4.63 & 0.63 & 4.63 & -0.43 \\
\hline rother & Midddle & $203.35 \pm 2.01$ & $199.27 \pm 3.74$ & 4,09 & 0,47 & 4,08 & -0.31 \\
\hline secasons) & Outer & $202.06 \pm 1.76$ & $199.05 \pm 3.57$ & 3.03 & 0.55 & 3.01 & -0.77 \\
\hline
\end{tabular}


This article has been accepted for inclusion in a future issue of this journal. Content is final as presented, with the exception of pagination.
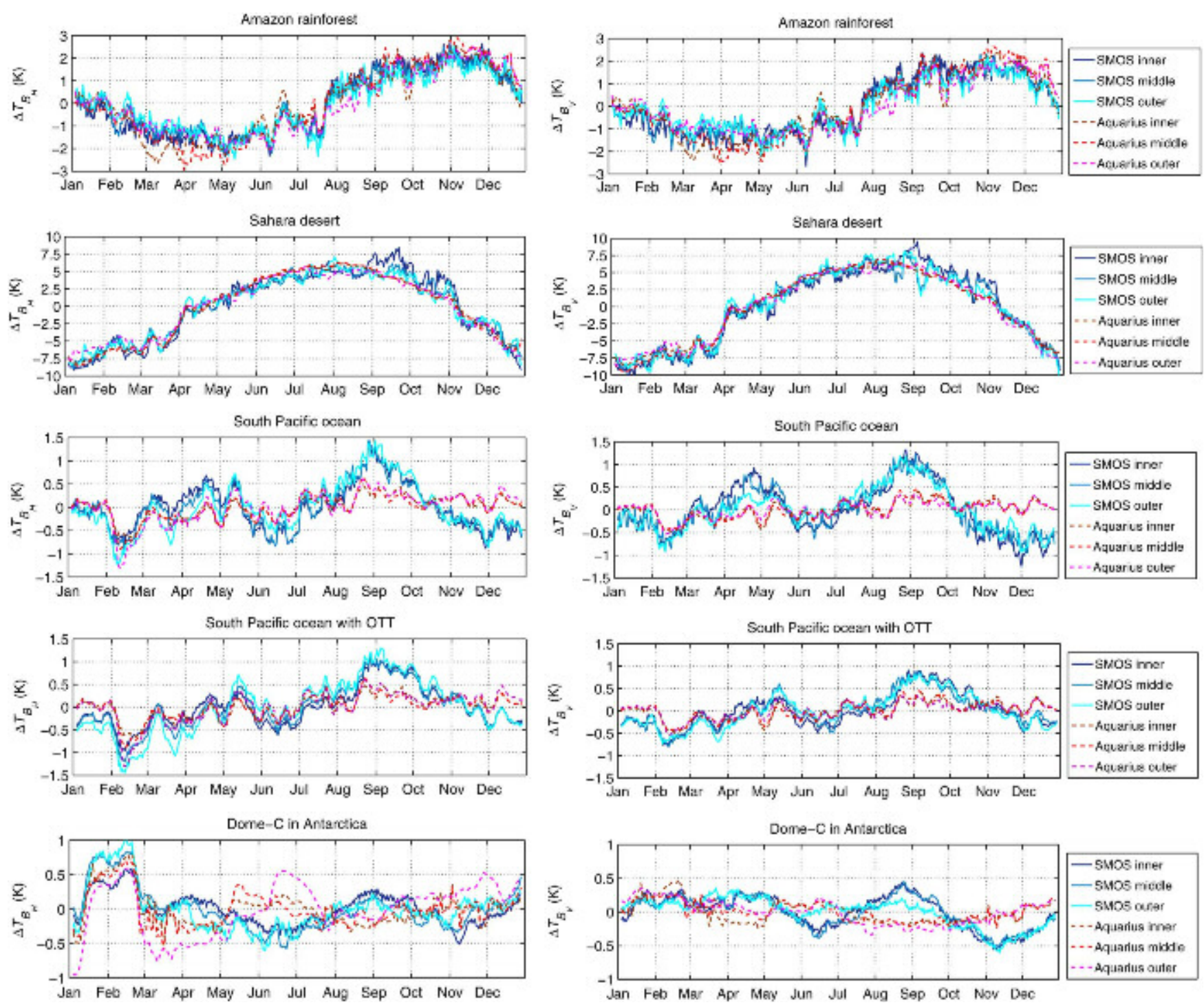

Fig. 7. SMOS (bluish solid lines) and Aquarius (reddish dashed lines) $T_{B}$ variations subtracting the corresponding yearly mean value ( $\Delta T_{B_{p o l}}=T_{B_{p o l}}-\overline{T_{B_{p o l}}}$, where the subscript pol indicates the polarization $\mathrm{H}$ or $\mathrm{V}$ for horizontal and vertical, respectively) over target areas sorted by rows: Amazon rainforest, Sahara desert, South Pacific ocean without OTT applied to SMOS data, South Pacific with OTT applied to SMOS data, and Dome-C in Antarctica. Polarizations are by columns: horizontal (left) and vertical (right). Different beams (inner, middle, and outer) are shown by colors on graduated shading.

elements greatly affecting emissivity, such as the bedrock surface [26] or the presence of subglacial lakes [27].

\section{DISCUSSION AND CONCLUSION}

For the first time, there are two satellite missions in orbit with L-band radiometers on-board: SMOS and Aquarius. In this work, an inter-comparison of SMOS $T_{B}$ versus Aquarius $T_{B}$ has been performed over four selected targets: 1) the Amazon rainforest, 2) the Sahara desert, 3) the South Pacific Ocean, and 4) the Dome-C zone in Antarctica. Radiometric observations, acquired independently for each instrument, are therefore compared over land, ice, and sea areas, covering a large dynamic range.

This paper differs from the previous works on SMOS and Aquarius comparisons on the use of a 7-day window averaging. The proposed technique allows to do inter-comparison in any latitude and to collect a fair amount of data for robust statistics. The length of the window should be chosen to ensure that $T_{B}$ values are preserved when averaging. Both ascending and descending orbits are used. The comparison is based on the analysis of the level of linearity, the correlation, and the differences between SMOS and Aquarius $T_{B}$, using daily statistics along the whole year 2012.

Main conclusions of this work are as follows:

1) There is a high correlation over land $(\mathrm{R}>0.9)$ and it decreases over sea $(\mathrm{R} \approx 0.23-0.68)$. Slope values obtained from a robust linear fit are close to 1 over land $(s \approx 0.86$ $1.21)$ and lower over sea $(s \approx 0.08-0.37)$. Slopes are systematically higher at horizontal than at vertical polarizations. Also, slopes are higher at high incidence angles.

2) The Aquarius L2 $T_{B}$ product has been produced using an ocean model as a reference during its calibration. In this study, an OTT obtained from an ocean model has been applied to SMOS data to reduce the pixel bias existing in the FOV. Results show the inter-comparison is significantly improved over sea when applying the OTT, with 
increasing correlation $(\mathrm{R} \approx 0.63-0.80)$ and slope values $(s \approx 0.30-0.42)$.

3) Aquarius is systematically measuring warmer $T_{B}$ than SMOS. There is a higher difference over land targets $(\sim 5-8 \mathrm{~K})$. This difference decreases over colder targets $(\sim 3-5$ K over ice, and $\sim 0.1-0.3 \mathrm{~K}$ over sea, after OTT). This indicates there may be a non-linear effect between the two radiometers, and not only a bias.

4) SMOS and Aquarius $T_{B}$ have similar seasonal cycles over land. Nevertheless, SMOS $T_{B}$ show higher seasonal variability than Aquarius over sea.

5) A seasonal effect is observed in the Dome-C region. The correlation associated to the Austral summer is high $(\mathrm{R} \approx 0.74-0.96)$ and it decreases in the other three seasons $(\mathrm{R} \approx 0.24-0.65)$. Also, two different slopes are shown in opposite sign (Dome-C Austral summer: $s \approx 0.30-1.56$, other seasons: $s \approx-0.11$ to -0.77 ).

6) The East Antarctic Plateau, particularly the Dome-C area has been used as a test site for calibrating and validating data of satellite-borne microwave radiometers since the $1970 \mathrm{~s}$ [22], [28], [29]. However, the analysis performed in this work evidences some spatial inhomegeneities in this area that can be detected with L-band radiometers, in line with the conclusions achieved in a recent airborne experiment [25]. Consequently, some studies for having a better understanding of Dome-C emissivity at L-band are required before using this area as a calibration target.

Any study using a long term enviromental data record that spans multiple L-band missions requires consistent input observations. Results presented on this work are a contribution to understand the differences between SMOS and Aquarius measurements. Also, they could help in deciding future target areas for a vicarious calibration or to validate in a better way the $T_{B}$ products from both radiometers using in-situ measurements of a particular area. These results could also help the definition of the calibration and/or validation of the SMAP radiometer as well.

\section{ACKNOWLEDGMENT}

The authors would like to thank J. Gourrion and S. Guimbard from the Institut de Ciències del Mar-Consejo Superior de Investigaciones Científicas (ICM-CSIC) for the support about the SMOS spatial pixel bias and for the assistance to use Aquarius data products, respectively. They also thank I. Corbella, F. Torres, and N. Duffo from the Universitat Politècnica de Catalunya (UPC) for their feedback during the evaluation of the results.

\section{REFERENCES}

[1] F. T. Ulaby, R. K. Moore, and A. K. Fung, "Fundamentals and radiometry," in Microwave Remote Sensing Active and Passive, vol. 1. Reading, MA, USA: Addison Wesley/Artech House, 1981.

[2] T. Schmugge, P. E. O'Neill, and J. R. Wang, "Passive microwave soil moisture research," IEEE Trans. Geosci. Remote Sens., vol. GE-24, no. 1, pp. 12-22, Jan. 1986.

[3] H. J. C. Blume and B. M. Kendall, "Passive microwave measurements of temperature and salinity in coastal areas," IEEE Trans. Geosci. Remote Sens., vol. GE-20, no. 3, pp. 394-404, Jul. 1982.

[4] Y. H. Kerr et al., "The SMOS mission: New tool for monitoring key elements of the global water cycle," Proc. IEEE, vol. 98, no. 5, pp. 666-687, May 2010.
[5] J. Font et al., "SMOS: The challenging sea surface salinity measurement from space," Proc. IEEE, vol. 98, no. 5, pp. 649-665, May 2010.

[6] D. M. Le Vine, G. S. E. Lagerloef, and S. E. Torrusio, "Aquarius and remote sensing of sea surface salinity from space," Proc. IEEE, vol. 98, no. 5, pp. 688-703, May 2010.

[7] K. D. McMullan et al., "SMOS: The payload," IEEE Trans. Geosci. Remote Sens., vol. 46, no. 3, pp. 594-605, Mar. 2008.

[8] D. M. Le Vine, G. S. E. Lagerloef, F. R. Colomb, S. H. Yueh, and F. A. Pellerano, "Aquarius: An instrument to monitor sea surface salinity from space," IEEE Trans. Geosci. Remote Sens., vol. 45, no. 7, pp. 2040 2050, Jul. 2007.

[9] D. Entekhabi et al., "The soil moisture active passive (SMAP) mission," Proc. IEEE, vol. 98, no. 5, pp. 704-716, May 2010.

[10] E. Kim et al., "L1 radiometer TB," in Proc. Soil Moisture Active Passive Mission 3rd SMAP Cal/Val Workshop, 2012 [Online]. Available: http:// smap.jpl.nasa.gov/files/smap2/5_KimE_L1rad.pdf

[11] M. A. Brown, F. Torres, I. Corbella, and A. Colliander, "SMOS calibration," IEEE Trans. Geosci. Remote Sens., vol. 46, no. 3, pp. 646-658, Mar. 2008

[12] J. Piepmeier, G. Feldman, G. S. E. Lagerloef, D. M. Le Vine, and S. H. Yueh, "Aquarius Radiometer Post-Launch Calibration for Product Version 2," Aquarius Project Document: AQ-014-PS-0015 Rev., Feb. 19, 2013.

[13] E. Anterrieu, Y. Kerr, F. Cabot, G. S. E. Lagerloef, and D. M. Le Vine, “A synergy between SMOS and Aquarius: Resampling SMOS maps at the resolution and incidence of AQUARIUS," in Proc. IEEE Int. Geosci. Remote Sens. Symp. (IGARSS), 2011, pp. 4142-4145.

[14] R. Bindlish, T. J. Jackson, T. Zhao, and M. Cosh, "Use of satellite observations in SMAP cal/val," in Proc. Soil Moisture Active Passive Mission 3rd SMAP Cal/Val Workshop, 2012 [Online]. Available: http:// smap.jpl.nasa.gov/files/smap2/26_Bindlish1.pdf

[15] F. Cabot, G. S. E. Lagerloef, Y. Kerr, and E. Anterrieu, "Intercalibration of SMOS and Aquarius over land, ice and ocean," in Proc. SMOS Aquarius Sci. Workshop, 2013 [Online]. Available: http://aquarius.umaine.edu/docs/ aqsmos2013_cabot.pdf

[16] K. Sahr, D. White, and A. J. Kimerling, "Geodesic discrete global grid systems," Cartogr. Geogr. Inf. Sci., vol. 30, no. 2, pp. 121-134, 2003.

[17] J. Bará, A. Camps, F. Torres, and I. Corbella, "Angular resolution of twodimensional, hexagonally sampled interferometric radiometers," Radio Sci., vol. 33, no. 5, pp. 1459-1473, 1998.

[18] A. Camps, M. Vall-llossera, I. Corbella, N. Duffo, and F. Torres, "Improved image reconstruction algorithms for aperture synthesis radiometers," IEEE Trans. Geosci. Remote Sens., vol. 46, no. 1, pp. 146-158, Jan. 2008.

[19] F. Torres et al., "Minimization of image distortion in SMOS brightness temperature maps over the ocean," IEEE Geosci. Remote Sens. Lett., vol. 9, no. 1, pp. 18-22, Jan. 2012.

[20] J. Gourrion, S. Guimbard, M. Portabella, and R. Sabia, "Toward an optimal estimation of the SMOS antenna-frame systematic errors," IEEE Trans. Geosci. Remote Sens., vol. 51, no. 9, pp. 4752-4760, Sep. 2013.

[21] G. Macelloni, M. Brogioni, P. Pampaloni, A. Cagnati, and M. Drinkwater, "DOMEX 2004: An experimental campaign at Dome-C Antarctica for the calibration of spaceborne low-frequency microwave radiometers," IEEE Trans. Geosci. Remote Sens., vol. 44, no. 10, pp. 2642-2653, Oct. 2006.

[22] G. Macelloni et al., "Ground based L-band emission measurements at Dome-C Antarctica: The DOMEX-2 experiment," IEEE Trans. Geosci. Remote Sens., vol. 51, no. 9, pp. 4718-4730, Sep. 2013.

[23] W. H. DuMouchel and F. L. O'Brien, "Integrating a robust option into a multiple regression computing environment," in Proc. 21st Symp. Interface Comput. Sci. Statist., 1989, pp. 297-302.

[24] N. Floury, M. Drinkwater, and O. Witasse, "L-band brightness temperature of ice sheets in Antarctica: Emission modelling, ionospheric contribution and temporal stability," in Proc. IEEE Int. Geosci. Remote Sens. Symp. (IGARSS), 2002, vol. 4, pp. 2103-2105.

[25] S. S. Kristensen, S. S. Sobjaerg, J. E. Balling, and N. Skou, "EMIRAD Data: Presentation \& Analysis, Version 1.2," DOMECair Campaign, DTU Space, Nov. 12, 2013 [Online]. Available: https://earth.esa.int/documents/10174/ 134665/DOMECair-Data-v1_2

[26] P. Fretwell et al., "Bedmap 2: Improved ice bed, surface and thickness datasets for Antarctica," Cryosphere, vol. 7, pp. 375-393, 2013.

[27] A. Wright and M. Siegert, "A fourth inventory of Antarctic subglacial lakes," Antarctic Sci., vol. 24, no. 6, pp. 659-664, 2012.

[28] J. P. Hollinger, J. L. Pierce, and G. A. Poe, "SSM/I instrument evaluation," IEEE Trans. Geosci. Remote Sens., vol. 28, no. 5, pp. 781-790, Sep. 1990.

[29] M. Fily and J. P. Benoist, "Large-scale statistical study of scanning multichannel microwave radiometer (SMMR) over Antarctica," J. Glaciol., vol. 37, no. 125, pp. 129-139, 1991. 


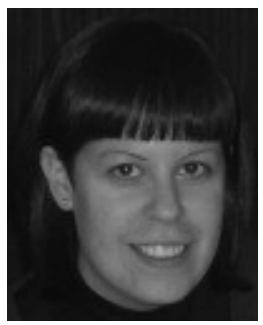

Miriam Pablos (S'14) was born in Barcelona, Spain, in 1984. She received the M.S. degree in telecommunication engineering from the School of Telecommunications Engineering, Universitat Politècnica de Catalunya (UPC), Barcelona, Spain, in 2010.

In 2009, she joined the Remote Sensing Laboratory Group, Department of Signal Theory and Communications, UPC, where she has been involved in the research of the thermal sensitivity analysis of the Microwave Imaging Radiometer by Aperture Synthesis (MIRAS) instrument of the ESA's Soil Moisture and Ocean Salinity (SMOS) mission, particularly in the characterization of the power measurement system over the physical temperature, during the pre-commissioning and commissioning phases. From 2010 to 2011, she was researching on interferometric radiometers at near-field devoted to security applications. Currently, she is pursuing the Ph.D. degree at the UPC and the SMOS Barcelona Expert Centre (SMOS-BEC), Barcelona, Spain, working on the assessment of the SMOS and Aquarius brightness temperature products, with a Formación Personal Investigador (FPI) grant of the Spanish Ministry of Economy and Competitiviness.

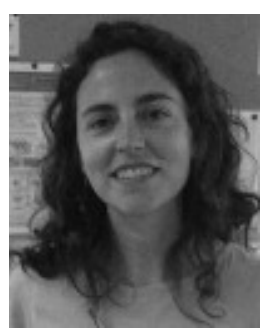

María Piles (S'05-M'11) was born in Valencia, Spain, in 1982. She received the M.S. and Ph.D. degrees in telecommunication engineering from the Universitat Politècnica de València (UPV), Valencia, Spain, in 2005, and from the Universitat Politècnica de Catalunya (UPC), Barcelona, Spain, in 2010, respectively.

In 2008, she was a visiting Ph.D. student with the Department of Civil and Environmental Engineering, Massachusetts Institute of Technology, Boston, USA. In 2010, she joined as a Research Fellow with the Department of Civil and Environmental Engineering, University of Melbourne, Melbourne, Australia. Since 2011, she has been a Research Scientist at UPC and is based at the Soil Moisture and Ocean Salinity Barcelona Expert Centre (SMOS-BEC). Her research interests include remote sensing for Earth observation, with special emphasis in radiometers, radars and visible/infrared sensors, retrieval of soil moisture and vegetation parameters, and development of downscaling algorithms and data fusion techniques. She has participated in eight research projects funded by national and international agencies, mainly related to the ESA's SMOS and the NASA's SMAP missions.

Dr. Piles received the Med-Storm Prize for Young Researchers in the Plinius conference (2011) and the UPC special doctoral award in Information Technology and Communication (2012). Since 2012, she has been the Secretary of the IEEE Geoscience and Remote Sensing Society (GRSS) Spanish chapter. She has published 12 papers in peer-reviewed journals, and more than 60 international conference presentations.

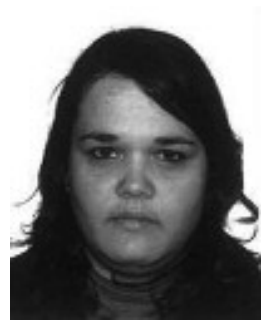

Verónica González-Gambau was born in Huesca, Spain, in 1981. She received the M.S. and Ph.D. degrees in telecommunication engineering from the School of Telecommunication Engineering, Universitat Politècnica de Catalunya (UPC), Barcelona, Spain, in 2006 and 2012, respectively.

In 2006, she joined the Passive Remote Sensing Group of the Signal Theory and Communications Department, UPC, where she was involved in the Soil Moisture and Ocean Salinity (SMOS) payload on-ground characterization in the framework of SMOS pre-commissioning activities. She was also collaborating with the SMOS Level 1 software development and data analysis of the Microwave Imaging Radiometer by Aperture Synthesis (MIRAS) instrument validation campaigns. In 2007, she was a UPC Researcher in collaboration with the SMOS Barcelona Expert Centre (SMOS-BEC), Barcelona, Spain. Currently, she is a Research Scientist at the Institut de Ciéncies del Mar-Consejo Superior de Investigaciones Científicas (ICM-CSIC), the SMOS mission coleading institution, where she is responsible for the advance Level 1 error correction techniques and in-orbit validation procedures. Also, she is working on the development of algorithms for the SMOS brightness temperatures improvement, and assessing the impact of these techniques on the quality of the geophysical retrievals.

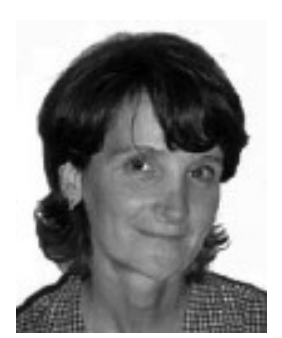

Mercè Vall-llossera (SM'99) received the M.S. and $\mathrm{Ph} . \mathrm{D}$. degrees in telecommunications engineering from the Universitat Politècnica de Catalunya (UPC), Barcelona, Spain, in 1990 and 1994, respectively.

She has been lecturing and doing research with the Department of Signal Theory and Communications, UPC, from 1990 until 1997, as an Assistant Professor, and from 1997 until present, as an Associate Professor. She spent a sabbatical year at the Concordia University, Montreal, QC, Canada, with the scholarship of the "Programme Québécois de Bourses d'excellence" (1996-1997): "Stages de Formation postdoctorale au Québec pour jeunes diplomés étrangers," analyzing the effect of mobile telephone to the human body. At the beginning, her research activities were related to numerical methods in electromagnetics, and antenna analysis and design. Since 2000, her research interests include passive remote sensing and geophysical parameters retrieval from L-band radiometric measurements. She has been participating in several projects for the preparation of the ESA's Soil Moisture and Ocean Salinity (SMOS) mission.

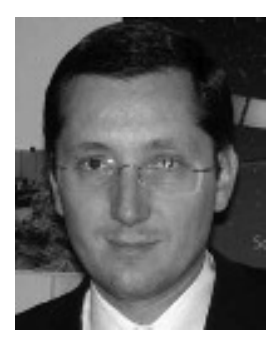

Adriano Camps (S'91-A'97-M'00-SM'03-F'11) was born in Barcelona, Spain, in 1969. He received the M.S. and Ph.D. degrees in telecommunications engineering from the Universitat Politècnica de Catalunya (UPC), Barcelona, Spain, in 1992 and 1996, respectively.

From 1991 to 1992 , he was with the ENS des Télécommunications de Bretagne, France, with an Erasmus Fellowship. Since 1993, he has been with the Electromagnetics and Photonics Engineering Group, Department of Signal Theory and Communications, UPC, where he was first an Assistant Professor and in 1997, an Associate Professor. Since 2007, he is a Full Professor. In 1999, he was on sabbatical leave at the Microwave Remote Sensing Laboratory, University of Massachusetts, Amherst, MA, USA. Since 1993, he has been deeply involved in the European Space Agency Soil Moisture and Ocean Salinity Earth Explorer Mission, and since 2001 on the use of GNSS-R techniques to perform the sea state correction needed to retrieve salinity from radiometric observations.

Dr. Camps received a number of awards for his research and teaching activies, among which the Research Distinction of the Generalitat de Catalunya (2002) for contributions to microwave passive remote sensing; the European Young Investigator Award (2004) of the European Science Foundation, the ICREA Academia award (2009), and the 1st (2000) and 7th (2010) Duran Farell Awards. He has published more than 125 peer-reviewed journal papers, and more than 250 international conference presentations.

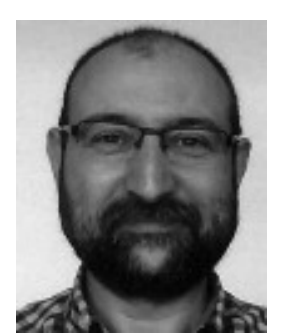

Justino Martínez was born in Girona, Spain, in 1966 He received the B.Sc. and Ph.D. degrees in physics from Autonomous University of Barcelona (UAB), Barcelona, Spain, in 1991 and 1995, respectively.

Currently, he is working as a Scientific Programmer in the Physical Oceanography Department, Institut de Ciències del Mar-Consejo Superior de Investigaciones Científicas (ICM-CSIC), Barcelona, Spain.

Dr. Martínez is a member of the Soil Moisture and Ocean Salinity Barcelona Expert Centre (SMOS-BEC), Barcelona, Spain. He is involved in the L3 and L4 SMOS products generation, developing methods and tools to retrieve sea surface salinity from brightness temperatures. His research interest include forward models and inversion methods 